\title{
Virtual Screening of Mimosa pudica Secondary Metabolites as Hyaluronidase B Potential Inhibitor to Prevent Vespa velutina Venom Spreading
}

\author{
Muhammad Asyraf Rijalullah ${ }^{1 *}$, Muhammad Alif Imam Pramudya ${ }^{1}$, Dalilatul Maisuroh ${ }^{1}$, Dhiyaa \\ Syahlaa Bianca Febrinnisa Zain ${ }^{1}$, Nia Kurniawan', Fatchiyah Fatchiyah ${ }^{1,2}$ \\ ${ }^{1}$ Department of Biology, Faculty of Mathematics and Natural Sciences, Brawijaya University, Jalan Veteran, Malang, East Java, \\ Indonesia, 65145 \\ ${ }^{2}$ Research Center for Smart Molecules of Natural Genetics Resources (SMONAGENES), Brawijaya University, Jalan Veteran, \\ Malang, East Java, Indonesia, 65145
}

Submission: 01 June 2021; Revised: 07 July 2021; Accepted: 14 July 2021

*Corresponding author: Muhammad Asyraf Rijalullah; e-mail: asyrafrijalullah@gmail.com; tel: +6281235923575

\begin{abstract}
Vespa velutina, also known as the Yellow-legged hornet, is a wasp species native to Asia with a large distribution area in Indonesia. Hyaluronidase B in a wasp venom acts as a "spreading factor", which is the key at the beginning of envenomation. Shameplant (Mimosa pudica), a common plant in Indonesia, has shown the potential to be a hyaluronidase $B$ inhibitor. This study aimed to analyze the potential of secondary metabolites in Shameplant as an inhibitor of $V$. velutina Hyaluronidase $B$ base on their molecular interactions and as a topical drug base on physicochemical characteristics. In silico computational studies is performed to predict the binding modes of M. pudica compounds and hyaluronidase B enzyme. The secondary metabolites were retrieved from the PubChem database and screened using SwissADME. The seven metabolite compounds were docked with Hyaluronidase B and hyaluronan by HEX Cuda 8.0.0 program. Hyaluronidase B was also docked with its native ligand (hyaluronan) to validate the docking study. Three dimensional and $2 D$ views were then evaluated using Discovery Studio 2016. Results of this study are all compounds do not have the same molecular interaction with the control. It defines no inhibition of the interaction on the active side. Mimopudine is the most potent inhibitor of hyaluronidase B based on its binding energy. While, jasmonic acid is the only compound that meets the physicochemical parameter of the topical drug.
\end{abstract}

Keywords: Virtual screening, Hyaluronidase B, Mimosa pudica, Vespa velutina,

\section{INTRODUCTION}

Case of hornet-stings-related deaths in Indonesia became a hot topic in early 2021. This "killer" hornet has been identified in the Vespa genus that is spread worldwide. One of the species is Vespa velutina, or commonly known as the Yellow-legged hornet, is a hornet species native to Asia with a distribution area in Indonesia and is known as an aggressive species [1]. V. velutina often builds nests in residential areas, where humans can attack. The attack occurred with a pheromone which triggered the colony to attack. Hornet stings are events that involve a complex component called venom [2]

Hyaluronidase B, commonly known as Ves v2, is an enzymatic component found in $V$. velutina venom. The structure of hyaluronidase has general similarities in various organisms, where these structures influence enzymatic activity. This enzyme acts as a "spreading factor" which is the key at the beginning of envenomation. Hyaluronidase in a hornet venom is classified as an allergen with a hyaluronidase catalytic mechanism based on the glycosaminoglycan degradation pathway [3-4]. Cleavage of $\beta-1,4$-glycosidic bonds occurs in the degradation process of hyaluronic acid [4]. The impact that occurs is a decrease in tissue viscosity, an increase in membrane permeability, and the exposed tissue becomes very permeable to venom components [5].

Shameplant (Mimosa pudica) originates from the Americas, but this plant is widespread in Indonesia. Mimosa pudica is classified as an invasive plant because its existence threatens the endemic plant [6]. A previous study [7] showed that the secondary metabolite compound Putri Malu could be a hyaluronidase inhibitor. However, this study still does not explain the molecular interactions that occur. Therefore, this research needs to be conducted to analyze the potential of secondary metabolites in Shameplant as an inhibitor of $V$. velutina Hyaluronidase B base on their molecular interactions and as a topical drug base on physicochemical characteristics, which is expected to be the first step in designing an anti-allergen. In addition, the use of Shameplant can also help to overcome ecological problems.

\section{RESEARCH METHODS}

\section{Materials}


Hyaluronan as native ligand (CID: 24759) and seven active compounds from $M$. pudica which used as ligands were retrieved from PubChem (https://pubchem.ncbi.nlm.nih.gov) base on KNApSAcK database (https://www.knapsackfamily.com/) (Table 1). Crystallized structures of $V$. velutina Hyaluronidase B (UniProt entry: COHLL5) were taken from UniProt (https://www.uniprot.org/). Druglikeness was defined based on SwissADME physicochemical properties.

Table 1. List of $M$. pudica active compounds

\begin{tabular}{ll}
\hline Compounds & CID \\
\hline Jasmonic acid (JA) & 5281166 \\
L-Mimosine (LM) & 440473 \\
Noradrenaline (NA) & 439260 \\
Turgorin (TG) & 442991 \\
2"-O-alpha-L-Rhamnosyl-6-C-fucosyl- & 44257957 \\
luteolin (LT) & \\
Cassiaoccidentalin B (CB) & 70698280 \\
Mimopudine (MP) & 100927206 \\
\hline
\end{tabular}

\section{Docking Simulations}

Protein (Hyaluronidase B) were prepared using Discovery Studio 2016 to remove water molecule and previous attached ligand. To minimise its energy, ligands (Native ligand and active compounds) were prepared using PyRx 8.0 [8]. Molecular docking has been run using Hex 8.0.0 CUDA software [9] with Shape+Electro+DARS for correlation type, while other parameters remain default. Preparation and Docking results saved in .Pdb format to be visualized and analyzed using Discovery Studio 2016 [10].

\section{RESULTS AND DISCUSSIONS}

\section{Topical Druglikeness}

Physicochemical properties of a compound have a close correlation with topical druglikeness. One of the seven secondary metabolites from $M$. pudica has good potential as a candidate for topical drug constituents (Table 2). Jasmonic acid meets the criteria for parameters MW $<400$, LogP between -1.0 and 4, safe skin reaction, and TPSA $<140 \AA^{2}$ [11-12]. Furthermore, this compound has the highest skin permeation coefficient.

\section{Molecular Docking}

Docking results between control and compound can be seen in Figure 1. Hyaluronidase-hyaluronan interaction was used as a negative control with a binding energy value of $350.3 \mathrm{~kJ} / \mathrm{mol}$. This interaction shows the presence of 5 residues, including Lys155, Lys166, Asn213, Glu162, and Asn214. All amino acid residues that bind to the hyaluronan have this type of hydrogen bond interaction. Five of the seven secondary metabolites of $M$. pudica showed higher binding energy values than the controls, including JA, MP, $\mathrm{CB}, \mathrm{NA}$, and TG. The interaction between JA and Hyaluronidase occurred at Glu204 and Arg158 with a binding energy of $-348.24 \mathrm{~kJ} / \mathrm{mol}$. CB has a binding energy value of $-349.04 \mathrm{~kJ} / \mathrm{mol}$ bound to the residues Ser189, Val199, Trp119, and Phe186. NA has a binding energy value of $348.61 \mathrm{~kJ} / \mathrm{mol}$, which is bound to the $\operatorname{Trp} 119$ residue. TG has a binding energy value of -348 , $93 \mathrm{~kJ} / \mathrm{mol}$, which is bound to Arg158, Glu204, Thr200, Glu154, and Lys207. MP has a binding energy value of $-347.37 \mathrm{~kJ} / \mathrm{mol}$ bound to the Glu204 and Glu154 residues. MP is a secondary metabolite compound with the largest binding energy as a complex, thus allowing inhibition of the hyaluronidase-hyaluronan interaction. However, none of the compounds had the same amino acid residues with the control (Table 3 ). It defines no inhibition of the interaction on the active site. Differences in amino acid residues indicate the binding site changes in hyaluronan after docking using JA, MP, CB, NA, and TG compounds. Conformation changes can affect catalytic activity, be it induction or inhibition. Induction is characterized by decreased binding energy and inhibition with an increase in binding energy [13]. V. velutina stings cause reactions by injecting venom via their ovipositors into their target [11]. Wasps and hornets mainly have three groups of components in their venom: small molecular weight peptides, high molecular weight proteins and other components that act as enzymes, toxins and allergens [1]. Hyaluronidases are enzymes that hydrolyze hyaluronan in human skin to increase tissue permeability to fluids. Hyaluronidase in snake and insect venom functions as a "spreading factor" by degrading host hyaluronic acid, thus allowing the spread of toxin [12].

MP is a compound with the most significant potential as a hyaluronidase B enzyme inhibitor of hyaluronidase-hyaluronan interactions. Inhibition of this interaction is expected to be a preventive step in the distribution of $V$. velutina venom due to the activity of the enzyme hyaluronidase B. Unfortunately, the use of MP as a topical drug still requires further treatment to increase its lipophilicity [14]. Furthermore, research related to topical drug design still requires several further steps as validation steps to determine the efficacy of these compounds. Primary molecular candidates need to be identified and analyzed first through in vitro or in vivo studies using physicochemical parameters and [13]. Moreover, a molecular dynamic analysis to determine the stability period of jasmonic acid compounds binds to hyaluronan as a reference for topical drug applications. 
Table 2. Physicochemical characteristic of seven $M$. pudica secondary metabolites

\begin{tabular}{cccccc}
\hline Compounds & $\begin{array}{c}\text { Molecular } \\
\text { weight }(\mathbf{g} / \mathbf{m o l})\end{array}$ & LogP & $\begin{array}{c}\text { Skin Permeation } \\
(\mathbf{c m} / \mathbf{h})\end{array}$ & $\begin{array}{c}\text { Skin } \\
\text { reaction }\end{array}$ & $\begin{array}{c}\text { TPSA } \\
\left(\AA^{\mathbf{2}}\right)\end{array}$ \\
\hline JA & 210.27 & 2.01 & $-23.22 \times 10^{-3}$ & No & 54.37 \\
LM & 196.18 & -1.96 & $-38.16 \times 10^{-3}$ & Irritant & 105.55 \\
NA & 169.18 & -0.17 & $-29.55 \times 10^{-3}$ & Acute toxic & 86.71 \\
TG & 411.32 & -10.36 & $-37.72 \times 10^{-3}$ & No & 231.72 \\
LT & 578.52 & -0.71 & $-37.29 \times 10^{-3}$ & Irritant & 239.97 \\
CB & 576.50 & -0.53 & $-36.14 \times 10^{-3}$ & No & 236.81 \\
MP & 337.33 & -2.64 & $-37.04 \times 10^{-3}$ & No & 159.97 \\
\hline
\end{tabular}

Table 3. Interacting residues in hyaluronidase B protein and hyaluronan with $M$. pudica bioactive compounds

\begin{tabular}{|c|c|c|c|c|}
\hline Interaction & Amino acid residue & Category & Type & $\begin{array}{c}\text { Binding energy } \\
(\mathrm{kj} / \mathrm{mol})\end{array}$ \\
\hline \multirow{8}{*}{$\begin{array}{l}\text { Hyaluronidase B X HA } \\
\text { (Control) }\end{array}$} & A:LYS155:HZ1 - :LIG1:O & \multirow{8}{*}{ Hydrogen Bond } & Conventional & \multirow{8}{*}{-350} \\
\hline & A:LYS166:HZ1 - :LIG1:O & & Conventional & \\
\hline & A:LYS166:HZ1 - :LIG1:O & & Conventional & \\
\hline & A:ASN213:HD21 - :LIG1:O & & Conventional & \\
\hline & A:ASN213:HD21 - :LIG1:O & & Conventional & \\
\hline & :LIG1:H - :A:GLU162:OE2 & & Conventional & \\
\hline & :LIG1:H - :A:GLU162:OE1 & & Carbon & \\
\hline & :LIG1:H - :A:ASN214:OD1 & & Carbon & \\
\hline \multirow{2}{*}{ Hyaluronidase-HA x JA } & A:LIG1:H - A:GLU204:O & \multirow{2}{*}{ Hydrogen Bond } & Conventional & \multirow{2}{*}{$-348,24$} \\
\hline & A:ARG158:CD - A:LIG1:O & & Carbon & \\
\hline \multirow{5}{*}{ Hyaluronidase-HA x LM } & A:LIG1:H - A:PRO255:O & & Conventional & \multirow{5}{*}{$-353,43$} \\
\hline & A:LIG1:HA - A:ASP291:OD1 & Hydrogen Bond & Carbon & \\
\hline & A:LIG1:H - A:SER254:O & & Carbon & \\
\hline & A:ASP291:OD2 - A:LIG1 & Electrostatic & Pi-Anion & \\
\hline & A:LIG1 - A:VAL245 & Hydrophobic & Pi-Alkyl & \\
\hline
\end{tabular}

\begin{tabular}{|c|c|c|c|c|}
\hline Hyaluronidase-HA x NA & $\begin{array}{l}\text { A:TRP119 - A:LIG1 } \\
\text { A:TRP119 - A:LIG1 }\end{array}$ & Hydrophobic & Pi-Pi Stacking & $-348,61$ \\
\hline \multirow{5}{*}{ Hyaluronidase-HA x TG } & A:ARG158:HH12 - A:LIG1:O & \multirow{4}{*}{ Hydrogen Bond } & Conventional & \multirow{5}{*}{$-348,93$} \\
\hline & A:LIG1:H - A:GLU204:O & & Conventional & \\
\hline & A:LIG1:H - A:THR200:O & & Conventional & \\
\hline & A:LIG1:H - A:GLU154:OE1 & & Carbon & \\
\hline & A:LIG1 - A:LYS207 & Hydrophobic & Pi-Alkyl & \\
\hline \multirow{7}{*}{ Hyaluronidase-HA x LT } & A:PHE42:HN - A:LIG1:O & \multirow{2}{*}{ Hydrogen Bond } & Conventional & \multirow{7}{*}{$-357,8$} \\
\hline & A:LIG1:H - A:SER299:O & & Conventional & \\
\hline & A:LIG1:C - A:MET18 & \multirow{5}{*}{ Hydrophobic } & Alkyl & \\
\hline & A:PHE17 - A:LIG1:C & & Pi-Alkyl & \\
\hline & A:TYR51 - A:LIG1:C & & Pi-Alkyl & \\
\hline & A:LIG1 - A:ILE94 & & Pi-Alkyl & \\
\hline & A:LIG1 - A:PRO96 & & Pi-Alkyl & \\
\hline \multirow{3}{*}{ Hyaluronidase-HA x MP } & A:LIG1:H - A:GLU204:OE2 & Hydrogen Bond & Conventional & \multirow{3}{*}{$-347,37$} \\
\hline & A:LIG1:H - A:GLU204:OE2 & Hydrogen Bond & Carbon & \\
\hline & A:GLU154:OE1 - A:LIG1 & Electrostatic & Pi-Anion & \\
\hline
\end{tabular}


Hyaluronan (control)

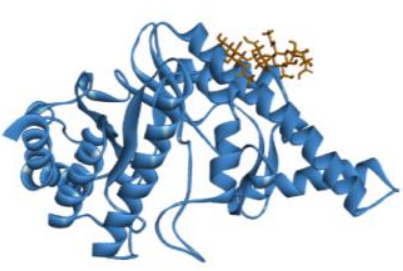

a1

2"-O-alpha-L-Rhamnosyl-6-C-fucosyl-luteolin

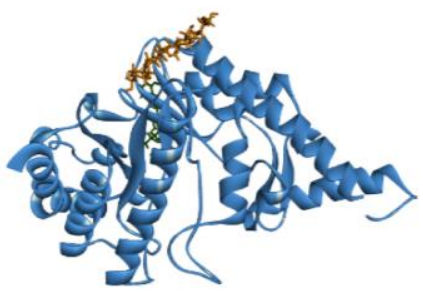

c1

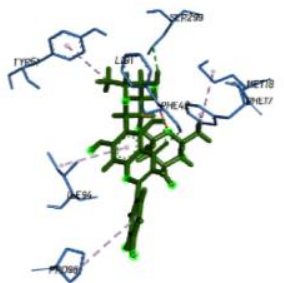

c2

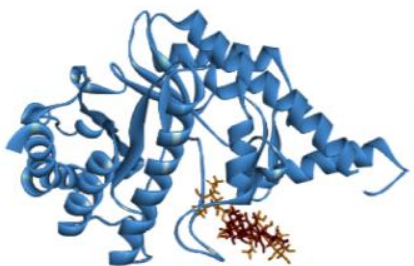

b1
Cassiaoccidentalin B

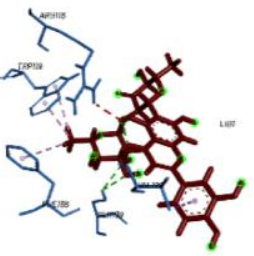

b2

Mimopudine

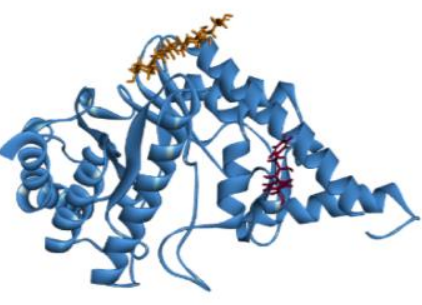

d1

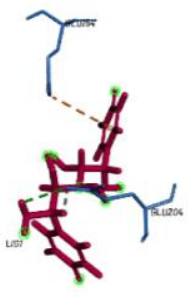

d2

L- Mimosine

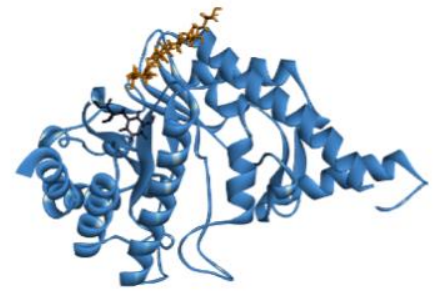

e1

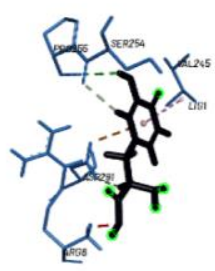

e2

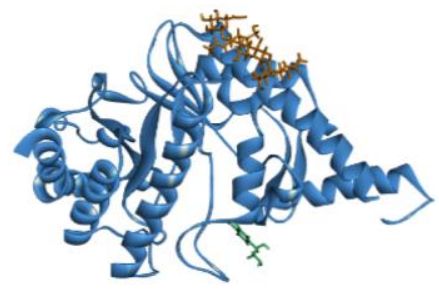

f1

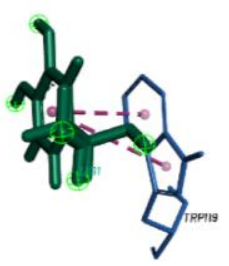

f2
Jasmonic acid

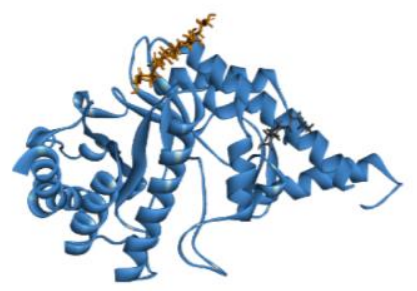

g1

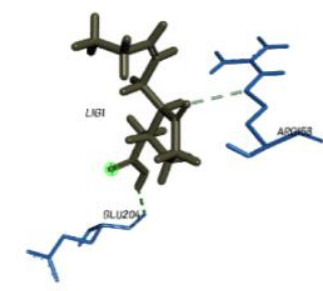

g2

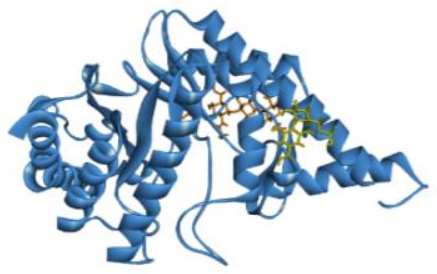

h1

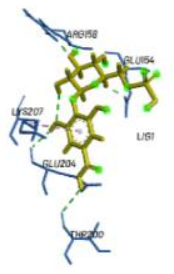

h2

Figure 1. Docking results between complex of Hyaluronidase B- M. pudica secondary metabolite compounds with Hyaluronan, (a1) Hyaluronidase B-Hyaluronan (control), (b1) Hyaluronidase B-CB-Hyaluronan, (c1) Hyaluronidase B-LT-Hyaluronan, (d1) Hyaluronidase B-MP-Hyaluronan, (e1) Hyaluronidase B-LMHyaluronan, (f1) Hyaluronidase B-NA-Hyaluronan, (g1) Hyaluronidase B-JA-Hyaluronan, (h1) Hyaluronidase B-TG-Hyaluronan and 3D ligan-hyaluronidase B interaction (a2) Hyaluronan-Hyaluronidase B, (b2) CBHyaluronidase B, (c2). LT-Hyaluronidase B, (d2) MP-Hyaluronidase B, (e2) LM- Hyaluronidase B, (f2). NAHyaluronidase, (g2) JA-Hyaluronidase B, (h2) TG-Hyaluronidase B. 


\section{CONCLUSION}

None of the compounds had the same amino acid residues as the control. It defines no inhibition of the interaction on the active site. Mimopudine is the most potential inhibitor of hyaluronidase $\mathrm{B}$ base on its binding energy though jasmonic acid is the only compound that meets physicochemical parameter of topical drug.

\section{ACKNOWLEDGEMENT}

The author would like to thank the bioinformatics lecturers and assistant for helping us to develop and finish this research article.

\section{REFERENCES}

[1] Herrera, C., M. Leza, E. Martinez-Lopez. 2020. Diversity of compounds in Vespa spp. venom and the epidemiology of its sting: a global appraisal. Archives of Toxicology. 94: 3609-3427.

[2] Vachvanichsanong, P., Dissaneewate, P., Mitarnun, W.,1997. Non-fatal acute renal failure due to wasp stings in children. Pediatric Nephrology. 11 (6): 734-736.

[3] Alfaya, A.T., Soriano, G.V., Soto, M.T., Vega, C.A., Vega, G.J.M., Alonso, L.A., Antolin, A.D., Carballada, G.F.J., Dominingues, N.C., Gutierrez, F.D., Marques, A.L., Martinez, A.A., Martinez., S.I.M., Moreno, A.A., Puente, C.Y. Ruin, L.B.Sanchez, M.L. 2017. Key Issues in Hymenoptera Venom Allergy: An Update. J. Investig. Allergol. Clin. Immunol. 27(1): 19-31.

[4] Bala, E., R. Hazarika, P. Singh, M. Yasir, R. Shrivastava. 2018. A biological overview of Hyaluronidase: A venom enzyme and its inhibition with plants materials. ICMPC. 6406-6412.

[5] David, W. 1993. Hyaluronidase. British Journal of Anaesthesia. 71: 422-425.
[6] Barneby, R.C. 1991. Sensitivae censitae: a description of the genus Mimosa Linnaeus (Mimosaceae) in the New World. Memoirs of the New York Botanical Garden. New York, USA: New York Botanical Garden. 65(3): 835.

[7] Girish., K.S., H.P. Mohanakumari, S. Nagaruju, B.S. Vishwanath, K. Kemparaju. 2004. Hyaluronidase and protease activities from Indian snake venoms: neutralization by Mimosa pudica root extract. Fitoterapia. 75: 378-380.

[8] Dallakyan, S. \& Olson, A.J. 2015. SmallMolecule Library Screening by Docking with PyRx. Methods in molecular Biology. 1263:243-250

[9] David W. Ritchie, Dima Kozakov, and Sandor Vajda. 2008. Accelerating Protein-Protein Docking Correlations Using A SixDimensional Analytic FFT Generating Function. Bioinformatics. 24(17): 1865-1873

[10] BIOVIA, Dassault Systemes. 2016. Discovery Studio 2016. San Diego

[11] Chandrashekar, N.S. \& Rani, R.H.S. 2008. Physicochemical and Pharmacokinetic Parameters in Drug Selection and Loading for Transdermal Drug Delivery. Indian $J$ Pharm Sci. 70(1): 94-96.

[12] Chagas, C. M., S. Moss, \& L. Alisaraie. 2018. Drug metabolites and their effects on the development of adverse reactions: Revisiting Lipinski's Rule of Five. International Journal of Pharmaceutics. 549(1-2): 133-149.

[13] Qiu, Y., Chen, Y., Zhang, G.G.Z., Yu, L., Mantri, R.V. Developing Solid Oral Dosage Form: Pharmceutical Theory and Practice. Academic Press.

[14]Arif, F. \& Mollie W. Hymenoptera stings. Statpearls Publishing. https://www.ncbi.nlm.nih.gov/books/NBK 518972. Accessed 20 April 2021. 